\title{
Mentoring Secondary Novice Teachers to Develop the Academic Language of English Language Learners
}

\author{
Susan O'Hara, $\mathrm{PhD}$ \\ University of California, Davis, Davis, California, United States \\ (iD) https://orcid.org/0000-0001-5265-4004 \\ Joanne Bookmyer, $\mathrm{PhD}$ \\ University of California, Davis, Davis, California, United States \\ (iD) https://orcid.org/0000-0002-4012-2999 \\ Robert Pritchard, $\mathrm{PhD}$ \\ EPF for Teaching, Sacramento, California, United States \\ Robin Martin, PhD \\ University of California, Davis, Davis, California, United States
}

Contact: sueohar@gmail.com

\section{Abstract}

This exploratory, qualitative study examines the foundational knowledge and instructional methods needed for academic language teaching of English language learners (ELLs). It also examines how mentoring practices can build secondary content-based novice teachers' instructional capacity in this area. The study uses synthesized data from two independent studies to contextualize findings on essential instructional practices within the process of mentoring new teachers. Three themes emerged: novices need the foundational, theoretical and practical knowledge underlying essential practices for academic language development; essential practices must be articulated in detail for enactment by teachers; and balancing explicit and immersive academic language instruction is a major paradigm shift for novices. Implications for mentor and teacher professional development are discussed, as mentors are key to supporting the uptake of dynamic instructional methods needed to enact essential practices. While mentoring is a common strategy for supporting new teachers, few models exist for how mentors can support new teachers with building the academic language development of ELLs. Further, few studies examine mentoring exchanges that can promote teachers' understanding and practices to support ELL students' academic language development. Limitations of the study include sample size and use of varied respondent data sets.

Keywords: mentoring, novice teachers, academic language development, English language learners, professional development, secondary education

Date Submitted: September 6, 2018 | Date Published: March 26, 2020

\section{Recommended Citation}

O'Hara, S., Bookmyer, J., Pritchard, R., \& Martin, R. (2020). Mentoring secondary novice teachers to develop the academic language of English language learners. Journal of Educational Research and Practice, 10, 26-40. https://doi.org/10.5590/JERAP.2020.10.1.02 


\section{Introduction}

In the fall of 2016, English language learners (ELLs) made up 9.8\% (4.6 million) of U.S. public school enrollment (National Center for Education Statistics, 2019). The demographics and needs of ELLs are varied, as this group includes students with disabilities, transitory migrant students, and recent immigrants or newcomers. At the same time that ELLs are struggling to keep up with their peers, the new Common Core State Standards require higher levels of understanding of academic language (i.e., reading and listening) and productive academic language (i.e., speaking and writing) in mathematics, English language arts, history and social studies, science, and technical subjects for all students.

Expectations for students' use of academic language require teachers to provide extra support to ELLs, as they learn both routine and disciplinary-specific methods of communicating. However, content area teachers report being underprepared to meet the academic needs of ELLs, let alone focus on academic language development of ELLs in their content areas (Gándara \& Rumberger, 2009; Lucas \& Grinberg, 2008). Underdeveloped knowledge of academic language and how to use it is a major contributor to gaps in achievement between ELLs and dominant-language-proficient students (Samson \& Collins, 2012; Short \& Fitzsimmons, 2007). Educators and researchers have suggested that developing novice teachers' knowledge and practices in areas specific to ELL instruction and, more specifically, academic language instruction within content areas is critical yet underresearched (Casteel \& Ballantyne, 2010; McGraner \& Saenz, 2009; Shea, Sandholtz, \& Shanahan, 2018; Villegas, SaizdeLaMora, Martin, \& Mills, 2018; Vogt, 2009).

Induction program mentoring is a widespread approach to supporting novice teachers. Although research on the impact of mentoring has been uneven, a more extensive examination of the complex aspects of mentoring could affect the ways teachers enact practices (Stanulis \& Brondyk, 2013). This article contributes to the limited research base by exploring targeted mentoring on high-leverage academic language development practices, in the context of an induction program, that hold potential to support both mentors and new teachers with developing these skills.

\section{Challenges of Novices and Mentor Support}

Support for novice teacher learning is imperative to establishing quality professionals. New teachers often enter classroom teaching with limited information on meeting the needs of ELLs, and some enter with limited foundational knowledge of academic language development. Many secondary-level teachers of subjects other than English language arts do not view themselves as teachers of language and have little knowledge about how to infuse academic language into each content area. To promote students' access to information, teachers need to develop foundational knowledge about language demands of the text and tasks they expect students to manage. In addition, teachers must include language objectives in lessons plans and understand secondlanguage acquisition. Although new teachers may have been exposed to accommodations for ELLs in a preservice program, they often lack practical tools and opportunities to practice their use in context with students under the supervision of an experienced supervisor (McDonald, 2005; Merino, 1999). Novices thus need expanded support in both foundational knowledge and practices that promote academic language development.

In recent decades, mentoring programs have become a dominant form of induction support for novice teachers. Teacher mentoring programs not only vary widely in content, focus, duration, and intensity of support provided to novices, but also with how they select, prepare, assign, and compensate mentors (Ingersoll \& Strong, 2011). Despite such fervor, mentoring programs often do not emphasize the importance of academic language development of ELLs. Given the critical need in the United States to support a growing ELL population and new teachers who are underprepared, mentoring programs must better instruct mentors on how to expand upon novice teachers' academic language development skills (Achinstein \& Athanases, 
2010a, 2010b; Gándara, Maxwell-Jolly, \& Driscoll, 2005). In an effort to fill the gap, the Achinstein, O'Hara, \& Zwiers (2012) study foregrounded strategic mentoring for new teachers of ELLs with an emphasis on academic language development. The study highlighted key elements of mentors' own knowledge and practice, including foundational knowledge of academic language development and ELLs. It focuses mentoring on core teaching practices, such as comprehensible input and output, and guiding mentoring conversations by explicitly targeting academic language development for ELLs. Targeted mentoring on deliberate and repeated elements of complex practices is critical for building novice teachers' academic language development skills.

\section{High-Leverage Academic Language Development Practices}

Across the literature on academic language, experts have highlighted the need for teachers to move beyond teaching only specialized vocabulary to including other aspects of academic language, such as a discipline's complex grammatical structure and discourse patterns (Carr, Carr, Sexton, \& Lagunoff, 2007; Zwiers, 2008); disciplinary habits, behaviors and cognitive features, such as the ability to think critically; and how to use language within particular functions and settings (Carrier, 2005; Echevarria, Vogt, \& Short, 2010; Schleppegrell, 2005). In fact, a study conducted by Bruna, Vann, and Escudero (2007) found that equating content vocabulary with academic English can inhibit students' learning of academic communication in science and more complex scientific concepts. Further, existing research on the academic language development of ELLs in content area classrooms suggests numerous effective teaching practices (August, McCardle, \& Shanahan, 2014; August \& Shanahan, 2017; Basurto, 1999; Bernhardt, 2005; Buchanan \& Helman, 1997; Echevarria et al., 2010; Huang, Berg, Siegrist, \& Damsri, 2017; Lucas \& Grinberg, 2008; O'Hara \& Pritchard, 2015; O'Hara, Pritchard, \& Zwiers, 2016; Shaila \& Zwiers, 2017; Short, 2017; Vaughn et al., 2017). However, effective instructional practices for developing ELLs' academic language identified in the research literature lack the level of articulation necessary to allow teachers to understand these practices and enact them in dynamic ways at the appropriate level for students (O'Hara, Pritchard, \& Zwiers, 2012). In order for mentors to help teachers to enact practices in their classrooms, the complexity of the practice must be evident, but manageable enough to allow teachers to visualize how the practice would fit into their own teaching methods.

In an effort to move beyond a broad set of effective practices, Pritchard and O'Hara (2013) conducted an empirical Delphi study to identify which instructional practices are most essential and offer the highest leverage for promoting the academic language development of adolescent ELLs across disciplines. Study findings converged on three essential, high-leverage practices: fostering academic interactions, fortifying academic output, and using complex text to develop academic language. Although these essential, highleverage practices are central to effective academic language instruction, the findings also suggested they alone do not get to the core of academic language teaching. Effective academic language teachers enact a set of dynamic instructional moves in support of these essential, high-leverage practices. However, absent from existing research literature on teacher professional development is how teachers negotiate these moves in the dynamic action of instruction. Therefore, developing models of professional development for mentors and teachers that are grounded in the necessary foundational knowledge and that identify and illustrate both essential instructional practices and the dynamic moves needed for their enactment, provide a potentially powerful approach for improving the quality of instruction for ELLs.

\section{Purpose and Research Questions}

This study reanalyzed data from two previous studies to distill (a) what experts identified as the foundational knowledge and instructional moves needed to support academic language development of ELLs and (b) how mentors can support teachers with negotiating those dynamic instructional moves by examining findings in the context of mentor-novice-teacher exchanges. 


\section{Method}

A convergent parallel research design was used to merge data from two independent studies to investigate the study research questions. The first was a case study (O'Hara \& Achinstein, 2011) that drew from the practice of experienced mentors from a university-based induction program. The second was an empirical Delphi study (Pritchard \& O'Hara, 2013) with an embedded qualitative component that drew from a national panel of scholars and educators. While the data sources are independent, the study design unifies the strengths of both previous studies through an integrated and synthesized analysis of both data sets. Cross-case analysis of the two independent data sources allowed us to contextualize study findings by examining the essential, highleverage instructional practices identified from the Delphi study within the practice of the mentoring case study. This approach helped us understand the importance and also the complexities of teaching and mentoring practices that ultimately support academic language development of ELLs.

\section{Data Collection and Analysis}

While data from the Delphi study established an empirical, consensus-based set of high-leverage practices, this study focuses analysis on the qualitative, open-ended response data, which captured expanded definitions of high-leverage practices, newly introduced practices, and additional aspects of instruction that were articulated as essential for teaching academic language. From the case study, only the open-ended questionnaire and focus group response data were used for analysis.

Research Question 1: What do expert scholars and experienced practitioners identify as knowledge and instructional moves needed to support the academic language development of ELLs?

Research Question 2: How, if at all, is academic language development for ELLs reflected in the professional development of new teachers during exchanges with mentors?

A sample of data from each study was analyzed by two researchers to construct categories and themes from emergent patterns (Merriam, 1998) for codebook development. From the mentor case data, only references specific to ELLs or academic language development were used to delineate categories. Categories were further informed by the research literature on academic language development and ELLs. Cross-case analysis revealed a high degree of convergence on common themes. Therefore, analysis of Research Question 1 is based on the synthesis of cross-cutting themes from both data sets with clear attribution of response reflected in the results section. Mentoring cases were reviewed based on themes established from Research Question 1. One mentor case was selected as the basis for a deeper exploratory analysis of Research Question 2. The case selected represented many of the themes from the Research Question 1 analysis and demonstrated the complexities mentors face in focusing novices on teaching ELLs. The selected case also revealed the possibilities of the knowledge base in action through mentoring a novice teacher in a culturally and linguistically diverse student population.

\section{Findings}

The first research question asked what expert scholars and experienced practitioners identify as knowledge and instructional moves needed to support the academic language development of ELLs. Analysis of the Delphi panel and mentor data produced three cross-cutting themes: foundational knowledge teachers need for effective academic language instruction, and two categories of dynamic instructional moves that are key to enacting essential, high-leverage practices (Table 1). 
Table 1. Cross-Cutting Themes: Knowledge and Instructional Moves

\begin{tabular}{lccc}
\hline \multicolumn{1}{c}{ Theme } & $\begin{array}{c}\text { Delphi } \\
(\boldsymbol{n}=\mathbf{2 1})\end{array}$ & $\begin{array}{c}\text { Mentors } \\
(\mathbf{n}=\mathbf{2 4})\end{array}$ & $\begin{array}{c}\text { Totals } \\
(\boldsymbol{n}=\mathbf{4 5})\end{array}$ \\
\hline $\begin{array}{l}\text { Foundational knowledge of academic language for ELLs } \\
\text { The art of scaffolding/guiding academic language development }\end{array}$ & $14(67 \%)$ & $\mathbf{2 2}(92 \%)$ & $36(80 \%)$ \\
$\begin{array}{l}\text { Negotiating a balance between explicit and immersive academic } \\
\text { language instruction }\end{array}$ & $19(90 \%)$ & $\mathbf{1 8}(75 \%)$ & $37(82 \%)$ \\
\hline
\end{tabular}

Note. ELL = English language learner.

\section{Foundational Knowledge of Academic Language for ELLs}

Analyses highlighted the need for teachers to have a foundational knowledge of first- and second-language acquisition, academic language development, and culturally relevant pedagogy. Further articulated was the need for teachers, in all content areas, to view themselves as language teachers and attend to academic language development in their instruction, as this practice should not be confined to English language arts teachers. In addition to the theoretical knowledge teachers need for effective academic language instruction, multiple respondents reported on the practical foundational knowledge needed to identify the language demands of texts and tasks and integrate language development objectives in support of content objectives. A math mentor relayed that once teachers "identify the learning demands of a lesson, the act of making them transparent to the students, providing word banks and other scaffolds, and asking students to practice using the academic language becomes easier to do.” Delphi panel data further suggested that helping teachers identify the language demands of tasks and texts can help them develop a more sophisticated perception of academic language, noting as they develop that skill they will see that these demands move beyond academic vocabulary to include syntactical and discursive features of academic language.

\section{The Art of Scaffolding and Guiding Academic Language Development}

Respondents commonly acknowledged the need to provide ELLs with a range of linguistic scaffolds in content area classrooms. The responses highlight the careful art of enacting instructional moves that introduce, as well as gradually remove, scaffolds to foster students' independent use of academic language. For example, a history mentor explained how a teacher might provide scaffolds to make texts accessible in the history classroom by "modifying/adapting primary documents in the history classroom [and] providing scaffolds (i.e., guided questions and graphic organizers) to facilitate working with documents." Both respondent groups emphasized that teachers effectively support and guide academic language development by providing linguistic scaffolding appropriate to students' language levels. One Delphi panelist explained that dynamic support and guidance happen in action when "teachers monitor students' language use." Delphi panelists also emphasized the importance of teachers understanding the dynamic nature of scaffolding instructional moves to successfully enact the essential, high-leverage practices.

An interesting aspect of scaffolding instructional moves highlighted by respondents was the importance for teachers to understand how to reduce scaffolds over time so that students build proficiency with academic language and can use the language of the discipline independently in authentic ways. The Delphi panel experts stressed the need for the gradual release of scaffolds and attention to overscaffolding, which suggests a more nuanced understanding of these instructional moves and perhaps a deeper conception about the detail at which these moves need to be articulated in order for teachers to enact them. As this is a move that more experienced teachers might enact, the fact that there were fewer mentor comments may reflect the context of working with novice teachers and meeting them where they are developmentally. 


\section{Negotiating a Balance Between Explicit and Immersive Academic Language Instruction}

The two critical forms of academic language instruction that emerged from respondent comments were the importance of explicit academic language instruction and the need for students to be immersed in academic language use. Explicit instruction involves directly teaching some aspect of academic language meaning or structure, which is important for enactment of essential academic language practices. For example, one Delphi panelist noted, "Teachers should pay attention to the language of the content and make sure that they explicitly plan to teach difficult components of academic language to students."

Immersive instruction involves structuring tasks and experiences that promote students' use of academic language in authentic ways. The need to immerse students in the authentic use of academic language was reflected in this Delphi panelist's comment: "What matters is the kinds of tasks and interactions which give opportunities for peer dialogue to move back and forth between more colloquial and more formal academic locutions, with a gradual improvement in the latter and its joint comprehensibility." The importance of providing students with opportunities for oral output using academic language (for example, pair-share or whole-class discussion) was also evidenced by another Delphi panelist's suggestion that opportunities to produce authentic, relevant, and comprehensible output and to negotiate tasks with language must be provided in multiple ways.

As a practical example, a history mentor described a lesson designed with a new teacher that frontloaded content interactively through iterative rounds of student-to-student dialogue. The lesson was based on various historical scenarios, followed by opportunities for writing about history content learned during the interaction, subsequently followed by the explicit teaching of related vocabulary. The structure of this activity would allow students to build understanding of related vocabulary from their scenario experiences.

While Delphi panelists' comments suggested a more nuanced understanding of these instructional moves, and perhaps a deeper conception about the detail at which these moves need to be articulated in order for teachers to enact them, cross-case respondent analysis revealed that both explicit and immersive instruction are central to successful teaching of ELLs. Overall, the consensus of both groups was that balancing explicit instruction with immersive language use required sophisticated skill with negotiating between both types of instruction, which was essential to the successful enactment of high-leverage practices. More importantly, respondents noted that the dynamic needed to balance explicit and immersive academic language instructional moves is absent in most content area classrooms, as many content area teachers focus solely on explicit instruction of academic vocabulary.

\section{Vignette: Analysis of a Mentoring Exchange}

The second research question was concerned with how, if at all, academic language development for ELLs is reflected in the professional development of new teachers in the context of mentoring exchanges. One mentoring case was selected as a vignette, illustrative of the cross-cutting themes (Table 1) and the complexities of enacting the three high-impact practices.

The vignette examines the practice of a mentor (Mike) and novice teacher (Paul). Paul is a Chinese American, second-year teacher of ninth-grade English. Paul said a challenge for ELL students with learning English language arts is that many of his students did not have an opportunity to practice academic English because they did not have accessible study content for practice. Mike had deep knowledge and experience as a teacher and professional developer, especially focusing on supporting English learners and academic language development, which enabled researchers to see possibilities of the knowledge base in action. He described his 
vision of mentoring novices to focus on the needs of ELLs: "Mentors need to be able to provide ideas, models, and cultivate novices' abilities to evaluate students' language proficiencies and build from them."

Selected excerpts reveal the developmental trajectory of two exchanges: a conversation from the fall mentoring session and one from the following spring. The excerpts show how the mentor works with the developmental level of the novice. The mentor needs to both "pace and lead," keeping pace with the progress of the novice in his understanding, as well as to lead, at times, to higher levels of understanding and practice. As seen in the fall exchange, the novice has little awareness of what language objectives are, and that his objectives stay at the academic vocabulary level. The spring exchange captures the development of "messagelevel" understanding, as the mentor prompts for more scaffolding moves to enable the novices' conception of academic language as exclusively vocabulary. These excerpts also show how the mentor weaves notions of explicit and immersive academic language instruction together.

\section{Fall Exchange}

The initial lesson activity is focused on students sharing poems they have written, and providing each other with feedback. Here is how the fall exchange begins:

Mike (mentor): We're looking at creating new language objectives. Most of the time it would be one language objective for a lesson.

Paul (teacher): Is it like understanding vocabulary?

Mike (mentor): That could be it, but we're trying to get even deeper. You remember when you mentioned the thinking skills in one of our sessions? What is the language you want them to produce to show that they are getting the main idea or objective of the lesson? What is the language of the tasks?

Here, Mike is developing practical foundational knowledge about constructing language objectives that align with content objectives. When Paul reveals a conception of language objectives as limited to vocabulary, Mike seeks to expand the teacher's understanding of the language of the "thinking skills" at that message or discourse level beyond vocabulary by building on an earlier conversation in which Paul had identified an interest in developing students' thinking skills in English language arts. Paul haltingly begins, "I guess there's not much content today for the objective, it's just so they can choose what poem to share." Through discussion, Paul strengthens the content objective: "To share their poems - to workshop. They're going to share and suggest and compliment, then reflect and revise." Mike seizes this opportunity to identify the language demands of this task and asks a series of questions to unpack the three levels of language demands at the word, sentence, and message/thinking:

Mike (mentor): “Suggest, compliment, reflect, revise.” So there’s some appropriate language involved in suggesting and complimenting.

Mike (mentor): What are the word level demands? Are there any particular vocabulary terms you want them to use?

Paul (teacher): Yeah, they're supposed to start using simile, metaphor, personification.

Mike (mentor): Use those as they discuss the poems? And, suggest? Any sentences or grammar demands? ... Is there something you want in the suggestion? More complex sentences?

Paul (teacher): I guess basically the sentence starters. We want them to start using the vocabulary, but I don't know in terms of syntax. 
Mike (mentor): I think you should add sensory detail when you explain. That's a nice complex sentence, this "when" clause here. And then a thinking skill demand? ...

In this exchange, Mike instructively coached Paul with developing a language objective aligned with his content objective. Later, Mike reflected on his work with Paul: "I bring up the importance of having clear language objectives beyond vocabulary.... [and] I tried to emphasize the importance of building students' abilities to work at the 'message level' of language, not just the grammar and word levels." Mike is trying to shift Paul's thinking about language objectives which in later exchanges could shape the kinds of activities/lessons Paul designs for his students, helping him to start to think about activities in which students are engaged using academic language at the message level and therefore would require immersive instruction.

\section{Spring Exchange}

Mike and Paul reflect on an observed lesson on summarizing skills for Romeo and Juliet. Paul was excited at how the vocabulary work went. Mike acknowledged that Paul is working to contextualize the vocabulary. He identifies some scaffolding moves Paul can use to support academic language development, and promotes the use of oral academic practice. During the exchange, Mike helps Paul to choose the appropriate scaffolding strategy for the particular moment and specific students, thus beginning to introduce the art of scaffolding as a dynamic instructional move. He also helps Paul develop academic language tasks that move beyond explicit instruction to more immersive instruction and use of the academic language.

Mike (mentor): I liked the fact that you introduced the words with the pictures and sample sentences. It was very clear and rich, and they would have to use them later on. You might have been able to model something also. In fact, you could even do it during the vocab practice, right at the end by asking students to use two of those words in a sentence. I think is a great practice related to the writing. Kind of solidifying it a little bit. And, you can give them a chance to think through and put a sentence together, even in pairs. In a pair-share, "Tell your partner what this word means, use it in a sentence about your life," something like that, a real quick engagement activity.

As the mentoring conversation progresses, Mike suggests that Paul have his students produce academic language orally that could be developed into their writing. This suggestion seeks to move from explicit instruction to immersive instruction, in which students can eventually employ more authentic exchanges using academic language related to summarizing, a thinking skill. To move to the discourse/message level, the novice teacher will need to balance explicit and immersive instruction. Again, Mike suggests scaffolding moves to model summarizing.

Mike (mentor): Try to get the students to practice what you would like to see in their writing; have them practice orally as they're working in groups and writing. It will eventually become a more natural, automatic thing that happens when they write. In the end, you could model the writing. You can model like you have a summary.

Near the end of the exchange, the mentor reinforces the notion of academic language at the message level (language of summary), and the dynamic scaffolding moves needed to promote that (providing and prompting, modeling), and alignment with language objectives.

Mike (mentor): Think about this idea of providing and prompting for the language within the language objectives. Think about the language that could really help them do that. Model both the content and the language, and identify the language of the particular thinking skill. In language arts, you're typically summarizing like you did today. You might be interpreting, you might be analyzing cause and effect, or taking different perspectives. Think about the kind of language that supports that. 
Mike ends the exchange with the concept of a cycle of analysis that helps to promote a habit of mind for thinking about the kind of language that supports the thinking skill that teachers want students to use. Excerpts from the fall and spring mentoring exchanges illustrated how mentors can, over time, shape novice teacher pedagogical and conceptual thinking from focusing exclusively on explicit instruction at the word level to exploring instruction for message-level disciplinary thinking skills, thus negotiating the balance between explicit instruction and immersive instruction.

\section{Discussion}

Missing from much of the current educational research are the specific instructional moves that teachers need to make to enact essential, high-leverage practices in content area classrooms. Study findings show the art of teaching academic language requires both theoretical and practical foundational knowledge. More importantly, findings suggest there are dynamic instructional moves, in the action of academic language teaching, that are essential to leveraging high-impact practices and building teacher instructional capacity. Both promises and complexities were identified in mentoring novice teachers to better support the academic language development of ELLs.

\section{The Art of Teaching Academic Language}

The "art" of teaching academic language occurs when dynamic instructional moves are responsive to the specific needs of students in the classroom. Prior research led to the articulation of a set of essential, highleverage practices for effective academic language teaching (O'Hara et al., 2013). This study suggests that underlying these practices is a foundational knowledge base, both theoretical and practical, that teachers need to understand to be effective academic language teachers. The findings of this study also reinforce the need for teachers to reconceptualize academic language as more than academic vocabulary and provide multiple opportunities for students to engage at the discourse/message level in their classrooms. The findings echo recent research highlighting the need for teachers to move beyond the instruction of academic vocabulary to include teaching other aspects of academic language at the syntax and discourse levels (Carr et al., 2007; Schleppegrell, 2005; Zwiers, 2008).

Beyond current research, results reveal that for teachers to provide an instructional environment that fosters academic interactions and authentic, disciplinary output, they need more than an expanded notion of academic language. Teachers need to be able to scaffold the academic language learning of their students, moving them toward independent use of this language. Teachers also need to be able to negotiate a balance between explicit and immersive academic language instruction in their teaching. This is especially difficult, and a major paradigm shift, for most novice teachers. Discourse in the field has suggested the advantages of either explicit or immersive instruction. The findings from this study challenge this dichotomy represented in the literature, which stresses a sole focus on either explicit or immersive instruction (Schleppegrell, 2004, 2005; Valdés, Bunch, Snow, Lee, \& Matos, 2005). The findings indicate that teachers need to do both, and they need to understand and utilize a set of instructional moves for balancing these types of instruction and scaffolding the academic language learning as it occurs.

\section{Building Teacher Capacity for Dynamic Instructional Moves in the Action of Academic Language Teaching}

Study findings also suggest that current articulations of essential high-leverage practices for academic language development (e.g., some existing observation protocol descriptions for teaching ELLs) are not enough to support teachers putting these into action in their classrooms. These practices leave educators ill equipped because of the static nature and the complexity of their articulation. This study finds that for 
teachers to truly understand and enact these practices, they need to understand foundational theoretical and practical knowledge, as well as the dynamic, instructional moves that underlie the practices. This has important implications for building teacher capacity in the action of academic language teaching. Teachers do not receive quality support of instructional practices in teaching ELLs, nor are instructional moves typically articulated at the correct detail to enact effective instruction in their classrooms.

Delphi panelists emphasized a set of dynamic instructional moves that were missing from current characterizations of high-impact practices. They highlighted that these high-impact practices were necessary but insufficient, and that without these detailed dynamic instructional moves, teachers could not achieve the results they intended. Thus, findings suggest that the set of instructional moves identified in this study may close the gap between a set of high-leverage practices and teachers moving toward instruction that supports academic language development for ELLs. These gap-closing moves expand the research literature on core teaching practices (e.g., Grossman et al., 2009; Lampert, 2010; Windschitl, Thompson, Braaten, \& Stroupe, 2012). Ultimately, the findings promote teacher support and professional development on essential highleverage practices. In addition, the dynamic instructional moves needed to enact these practices are missing in current professional development initiatives (Pritchard \& O’Hara, 2013).

\section{Promises and Complexities of Mentoring Novice Teachers to Develop Academic Language of English Language Learners}

Mentoring novices offers the promise of building foundational knowledge and guiding dynamic instructional moves for academic language development of ELLs. Because of the proximity of mentors to actual real-time classroom practices, compared to preservice teacher education, mentors can strategically impact novices' development. Through observations, immediate feedback, and lesson planning, mentors can take up dynamic and nuanced issues of addressing specific students in particular moments of classroom teaching.

Exchanges between Mike and Paul offer promising evidence of a mentor's ability to build a novice's foundational knowledge about language and content objectives, as well as the need to identify language demands of texts and tasks to inform language objectives. The exchanges also provided examples of how mentors can support the novice in establishing dynamic instructional moves focused on academic language development of ELLs. Specifically, the mentor provided scaffolding procedures, such as prompting and modeling, while helping the novice explore opportunities for student independence. These exchanges were intended to help the novice choose the appropriate scaffolding strategy for the particular moment and specific students, thus beginning to introduce the art of scaffolding as a dynamic instructional move. These interactions also sought to support the novice in developing a vision of student progress in obtaining independent academic language use.

The mentor also supported the novice's progress from explicit instruction to immersive instruction, in which students can eventually engage in more authentic exchanges using academic language related to summarizing, a thinking skill. The mentor consistently prompted the novice to understand the need to balance explicit instruction and immersive instruction to begin to think about how to implement that balance in action during instruction.

The study findings expand beyond the emergent research on mentoring to support ELLs and academic language development. In addition, the research builds foundational knowledge and instructional moves for academic language development of ELLs, as well as the importance of mentor knowledge needed to support teachers with concentrating on the broader needs of ELLs (Achinstein \& Athanases, 2010a). This study also extends earlier work that is more directly linked to mentoring for academic language development of ELLs (Achinstein et al., 2012) by revealing nuances of in-depth mentoring exchanges that target foundational and 
dynamic instructional moves, particularly regarding language objectives/demands, scaffolding/modeling, moving beyond word to message level, and negotiating explicit and immersive instruction.

The mentoring vignette also revealed central complexities in supporting a novice's teaching of academic language development of ELLs. The first complexity is related to the novice's developmental needs and understandings of articulating a content objective, let alone a language objective. To engage in academic language development, the novice must first be supported in clearly articulating a content objective, to which a language objective can become aligned.

Second, Paul's initial understanding of identifying language objectives and of academic language development was to identify key vocabulary words with which his students would struggle. For example, in the first exchange in which Paul asked regarding language objectives, "Is it like understanding vocabulary?" This is common awareness of academic language among teachers, and even more common with new teachers. The mentor must build some foundational knowledge about language demands of texts and tasks, and help the novice articulate language demands that not only lie at the vocabulary level, but at the sentence and message level. The two continued to discuss these levels throughout the year, which suggests the difficulty of these shifts for secondary content teachers, and the intentional moves a mentor needs to undertake to maintain a focus on the message level.

Third, the mentor faces complexities in supporting the novice to negotiate between promoting explicit instruction on academic language and more immersive instruction, particularly in the context of in-action decision-making. The mentor is instructing the novice on some explicit academic language strategies of modeling, prompting and providing, which are all related to scaffolding moves. The mentor is also moving toward immersive instruction that promotes oral output from students sharing in authentic discussions that allow for more natural use of academic language. Mentors know that novices need to focus on both. If teachers want students to discuss poetry using academic language, they cannot just immerse the students in an open discussion without the careful and explicit instruction on academic language. However, the vignette reveals how slow the process is in training a novice to balance explicit and immersive instruction, with the mentor offering small suggestions to incorporate immersive instruction. Ultimately, these complexities highlight the need for professional development to focus on foundational and practical concerns of promoting academic language development for novice teachers, who are new to many of these concepts and practices.

\section{Limitations}

Limitations of the study include the sample size and independent respondent data sets. The small sample was inherent to the original focus on a select group for the Delphi expert panel and the size of the induction program itself. Although findings were based on the synthesis of data produced from distinct research questions, clear attribution of response is noted in the analysis.

\section{Conclusions}

This study identified foundational knowledge and dynamic instructional moves that support ELL's academic language development, as well as complexities of enactment that arise in the context of mentoring new teachers. This study holds implications for researchers and practitioners alike. For research, more studies are needed on how effective these identified instructional moves are and, particularly, how negotiating the dynamic practices of explicit and immersive instruction impact novices' teaching and ELLs' content and academic language learning. More research is needed on the professional development practices targeting these moves. Research is also needed to examine the nature of mentor professional development required to build capacity for this work. 
For practitioners, implications may be threefold. First, for teacher preparation, the study revealed needed foundational knowledge to broaden understanding of academic language in the content areas. This might mean introducing syntax and discourse dimensions of language areas (beyond vocabulary development) in content area methods courses. It might also involve focusing on every teacher's role in academic language development of students, and the importance of identifying language demands and objectives aligned with content.

Second, for teacher support and mentoring, foundational work may be needed as well. Unlike preservice teaching, this foundational work can be linked to the specific student population and classroom context of the teacher. Teacher support and mentoring might need to examine the right balance for enacting high-leverage instructional practices as well as the careful art of negotiating the dynamics of explicit and immersive instruction in the context of the teacher's classroom. Such work could involve illustrating instructional moves with videos and using mentoring exchanges to deconstruct practices.

Third, the study holds implications for the kinds of mentoring professional development that may be needed to build this capacity. Professional development for mentors is limited or generic in most induction programs. Thus, mentor professional development needs greater attention to supporting teachers' academic language development of ELLs in all content domains. Further, such mentoring work could explore the mentoring practices needed to support novices' negotiating explicit and immersive instruction. To do so, mentor professional development would need to address the foundational knowledge and provide it at the right detail that enables understanding and uptake of practices. This could involve examining and practicing mentoring strategies to support instructional moves through mentor modeling, debriefing, and concrete illustrations of practice. In such professional development, mentors could share their transcripts or videos and engage in focused inquiry on their own, including their observations and conversations with teachers. Illustrating mentoring practices with vignettes or actual mentoring exchanges (like the one between Mike and Paul) may also be helpful in unpacking the strategic mentoring moves needed to support novices' academic language development of ELLs.

\section{References}

Achinstein, B., \& Athanases, S. Z. (2010a). Mentoring for equity: Focusing new teachers on English language learners. In J. Wang \& R.T. Clift (Eds.), Past, present, and future research on teacher induction: An anthology for researchers, policy makers, and practitioners (pp. 187-204). Rowman \& Littlefield.

Achinstein, B., \& Athanases, S. Z. (2010b). New teacher induction and mentoring for educational change. In M. Hargreaves, A. Lieberman, M. Fullan \& D. Hopkins (Eds.), Second international handbook of educational change (pp. 573-593). Springer.

Achinstein, B., O’Hara, S., \& Zwiers, J. (2012). Strategic mentoring for new teachers of English learners. Journal of Communication and Education, 11, 20-23.

August, D., McCardle, P., \& Shanahan, T. (2014). Developing literacy in English language learners: Findings from a review of the experimental research. School Psychology Review, 43, 490-498.

August, D., \& Shanahan, T. (2017). Developing literacy in second-language learners: Report of the National Literacy Panel on Language-Minority Children and Youth. Routledge.

Basurto, I. (1999). Conditions of reading comprehension which facilitate word problems for second language learners. Reading Improvement, 36, 143-148.

Bernhardt, E. (2005). Progress and procrastination in second language reading. Annual Review of Applied Linguistics, 25, 133-150. 
Bruna, K. R., Vann, R., \& Escudero, M.P. (2007). What's language got to do with it? A case study of academic language in a high school English learner science class. Journal of English for Academic Purposes, 6, $36-54$.

Buchanan, K., \& Helman, M. (1997). Reforming mathematics instruction for ESL literacy students. Eric Digest.

Carr, J., Carr, J. W., Sexton, U., \& Lagunoff, R. (2007). Making science accessible to English learners: A guidebook for teachers, updated edition. WestEd.

Carrier, K. A. (2005). Key issues for teaching English language learners in academic classrooms. Middle School Journal, 38, 4-9.

Casteel, C. J., \& Ballantyne, K. G. (2010). Professional development in action: Improving teaching for English learners. National Clearinghouse for English Language Acquisition \& Language Instruction Educational Programs.

Echevarria, J., Vogt, M., \& Short, D. (2010). Making content comprehensible for elementary English learners: The SIOP model. Allyn \& Bacon.

Gándara, P., Maxwell-Jolly, J., \& Driscoll, A. (2005). Listening to teachers of English language learners: A survey of California teachers' challenges, experiences, and professional development needs. Policy Analysis for California Education.

Gándara, P., \& Rumberger, R. W. (2009). Immigration, language, and education: How does language policy structure opportunity? Teachers College Record, 111, 750-782.

Grossman, P., Compton, C., Igra, D., Ronfeldt, M., Shahan, E., \& Williamson, P. (2009). Teaching practice: A cross-professional perspective. Teachers College Record, 111, 2055-2100.

Huang, J., Berg, M., Siegrist, M., \& Damsri, C. (2017). Impact of a functional linguistic approach to teacher development on content area student writing. International Journal of Applied Linguistics, 27, 331362.

Ingersoll, R. M., \& Strong, M. (2011). The impact of induction and mentoring programs for beginning teachers: A critical review of the research. Review of Educational Research, 81, 201-233.

Lampert, M. (2010). Learning teaching in, from, and for practice: What do we mean? Journal of Teacher Education, 61, 21-34.

Lucas, T., \& Grinberg, J. (2008). Responding to the linguistic reality of mainstream classrooms. In M. Cochran-Smith, S. Feiman-Nemser, \& J. McIntyre (Eds.), Handbook of research on teacher education: Enduring issues in changing contexts (3rd ed., pp. 606-636). Routledge.

McDonald, M. A. (2005). The integration of social justice in teacher education: Dimensions of prospective teachers' opportunities to learn. Journal of Teacher Education, 56, 418-435.

McGraner, K. L., \& Saenz, L. (2009, September). Preparing teachers forEnglish language learners (TQ Connection Issue Paper). National Comprehensive Center fo r Teacher Quality. https://files.eric.ed.gov/fulltext/ED543816.pdf

Merino, B. J. (1999). Preparing secondary teachers to teach a second language: The case of the United States with a focus on California. In C. Faltis \& P. M. Wolfe (Eds.), So much to say: Adolescents, bilingualism and ESL in the secondary school (pp. 225-254). Teachers College Press.

Merriam, S. B. (1998). Qualitative research and case study applications in education. Jossey-Bass.

National Center for Education Statistics. (2019). Local Education Agency Universe Survey, 2016-17. U.S. Department of Education. 
O’Hara, S., \& Achinstein, B. (2011). Report on Stanford University's Partner School Induction Program. Stanford University.

O’Hara, S., \& Pritchard, R. (2015). Using new technologies to engage and support English learners in mathematics classrooms. In P. Drew (Ed.), Cases on technology integration in mathematics education (pp. 144-161). IGI Global.

O'Hara, S., Pritchard, R., Huang, C., \& Pella, S. (2013). The teaching using technology studio: Learning to use new technologies through responsive teacher professional development. TESOL Journal, 4, 274-294.

O'Hara, S., Pritchard, R., \& Zwiers, J. (2012). Identifying academic language demands in support of the Common Core Standards. ASCD Express, 7, 17.

O’Hara, S., Pritchard, R., \& Zwiers, J. (2016). Academic Language and Literacy in Every Subject (ALLIES): A capacity-building approach to supporting teachers in Grades 4-8. In C.P. Proctor, A. Boardman, \& E. H. Hiebert (Eds.), Teaching emergent bilingual students flexible approaches in an era of new standards (pp. 197-214). Guilford Press.

Pritchard, R., \& O’Hara, S. (2013). Framing the teaching of academic language to English learners: A Delphi study of expert consensus. TESOL Quarterly, 51, 418-428.

Samson, J. F., \& Collins, B. A. (2012). Preparing all teachers to meet the needs of English language learners: Applying research to policy and practice for teacher effectiveness. Center for American Progress.

Schleppegrell, M. J. (2004). The language of schooling: A functional linguistics perspective. Routledge.

Schleppegrell, M. J. (2005). Technical writing in a second language: The role of grammatical metaphor. In L. J. Ravelli \& R. A. Ellis (Eds.), Analysing academic writing: Contextualized frameworks (pp. 172189). Continuum.

Shaila, M. Y., \& Zwiers, J. (2017). Academic language across disciplines. Journal of English Studies, 8, 275279.

Shea, L. M., Sandholtz, J. H., \& Shanahan, T. B. (2018). We are all talking: A whole-school approach to professional development for teachers of English learners. Professional Development in Education, 44, 190-208.

Short, D. J. (2017). How to integrate content and language learning effectively for English language learners. Eurasia Journal of Mathematics, Science and Technology Education, 13, 4237-4260.

Short, D. J., \& Fitzsimmons, S. (2007). Double the work: Challenges and solutions to acquiring language and academic literacy for adolescent English language learners: A report to Carnegie Corporation of New York. Alliance for Excellent Education.

Stanulis, R., \& Brondyk, S. (2013). Complexities involved in mentoring toward a high-leverage practice in the induction years. Teachers College Record, 115(10), 1-34.

Valdés, G., Bunch, G., Snow, C., Lee, C., \& Matos, L. (2005). Enhancing the development of students' language. In L. Darling-Hammond \& J. Bransford, (Eds.), Preparing teachers for a changing world: What teachers should learn and be able to do (pp.126-167). Jossey-Bass.

Vaughn, S., Martinez, L. R., Wanzek, J., Roberts, G., Swanson, E., \& Fall, A. M. (2017). Improving content knowledge and comprehension for English language learners: Findings from a randomized control trial. Journal of Educational Psychology, 109, 22-34.

Villegas A. M., SaizdeLaMora K., Martin A. D., \& Mills, T. (2018). Preparing future mainstream teachers to teach English language learners: A review of the empirical literature. The Educational Forum, 82,138-155. 
Vogt, M. (2009). Teachers of English learners: Issues of preparation and professional development. In F. Falk-Ross, S. Szabo, M. B. Sampson, \& M. M. Foote (Eds.), Literacy issues during changing times: A call to action (pp. 23-36). Texas A\&M University.

Windschitl, M., Thompson, J., Braaten, M., \& Stroupe, D. (2012). Proposing a core set of instructional practices and tools for teachers of science. Science Education, 96, 878-903.

Zwiers, J. (2008). Building academic language: Essential practices for content classrooms. Jossey-Bass.

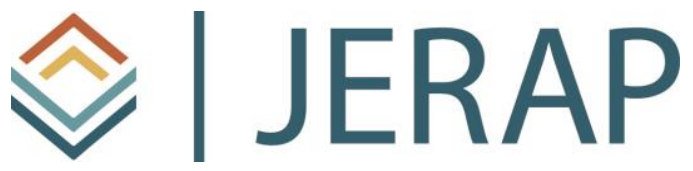

The Journal of Educational Research and Practice is a peerreviewed journal that provides a forum for studies and dialogue about developments and change in the field of education and learning. The journal includes research and related content that examine current relevant educational issues and processes. The aim is to provide readers with knowledge and with strategies to use that knowledge in educational or learning environments. JERAP focuses on education at all levels and in any setting, and includes peer-reviewed research reports, commentaries, book reviews, interviews of prominent individuals, and reports about educational practice. The journal is sponsored by the Richard W. Riley College of Education and Leadership at Walden University, and publication in JERAP is always free to authors and readers. 